\title{
Self-guided Cognitive Behavioral Therapy Apps for Depression: Systematic Assessment of Features, Functionality, and Congruence With Evidence
}

Laura Martinengo ${ }^{1}, \mathrm{MD}$; Anne-Claire Stona ${ }^{1}, \mathrm{MD}$; Konstadina Griva ${ }^{1}, \mathrm{PhD}$; Paola Dazzan ${ }^{2,3}, \mathrm{PhD}$; Carmine Maria Pariante $^{4}, \mathrm{MD}, \mathrm{PhD}$; Florian von Wangenheim ${ }^{5}$, PhD; Josip Car ${ }^{1,6}, \mathrm{MD}, \mathrm{PhD}$

${ }^{1}$ Centre for Population Health Sciences, Lee Kong Chian School of Medicine, Nanyang Technological University Singapore, Singapore, Singapore

${ }^{2}$ Department of Psychological Medicine, Institute of Psychiatry, Psychology and Neuroscience, King's College London, London, United Kingdom

${ }^{3}$ National Institute for Health Research Biomedical Research Centre at South London and Maudsley NHS Foundation Trust, London, United Kingdom

${ }^{4}$ Institute of Psychiatry, Psychology \& Neuroscience (IoPPN), King's College London, London, United Kingdom

${ }^{5}$ Professor of Technology Marketing, Department of Management, Technology \& Economics, ETH Zurich, Zurich, Switzerland

${ }^{6}$ Department of Primary Care and Public Health, School of Public Health, Imperial College London, London, United Kingdom

\section{Corresponding Author:}

Josip Car, MD, PhD

Centre for Population Health Sciences

Lee Kong Chian School of Medicine

Nanyang Technological University Singapore

Clinical Sciences Building, Level 18

11 Mandalay Road

Singapore

Singapore

Phone: 6569047005

Email: josip.car@ntu.edu.sg

\section{Abstract}

Background: Mental health disorders affect 1 in 10 people globally, of whom approximately 300 million are affected by depression. At least half of the people affected by depression remain untreated. Although cognitive behavioral therapy (CBT) is an effective treatment, access to mental health specialists, habitually challenging, has worsened because of the COVID-19 pandemic. Internet-based CBT is an effective and feasible strategy to increase access to treatment for people with depression. Mental health apps may further assist in facilitating self-management for people affected by depression; however, accessing the correct app may be cumbersome given the large number and wide variety of apps offered by public app marketplaces.

Objective: This study aims to systematically assess the features, functionality, data security, and congruence with evidence of self-guided CBT-based apps targeting users affected by depression that are available in major app stores.

Methods: We conducted a systematic assessment of self-guided CBT-based apps available in Google Play and the Apple App Store. Apps launched or updated since August 2018 were identified through a systematic search in the 42matters database using CBT-related terms. Apps meeting the inclusion criteria were downloaded and assessed using a Samsung Galaxy J7 Pro (Android 9) and iPhone 7 (iOS 13.3.1). Apps were appraised using a 182-question checklist developed by the research team, assessing their general characteristics, technical aspects and quality assurance, and CBT-related features, including 6 evidence-based CBT techniques (ie, psychoeducation, behavioral activation, cognitive restructuring, problem solving, relaxation, and exposure for comorbid anxiety) as informed by a CBT manual, CBT competence framework, and a literature review of internet-based CBT clinical trial protocols. The results were reported as a narrative review using descriptive statistics.

Results: The initial search yielded 3006 apps, of which 98 met the inclusion criteria and were systematically assessed. There were 20 well-being apps; 65 mental health apps, targeting two or more common mental health disorders, including depression; and 13 depression apps. A total of 28 apps offered at least four evidence-based CBT techniques, particularly depression apps. Cognitive restructuring was the most common technique, offered by 79\% (77/98) of the apps. Only one-third of the apps offered suicide risk management resources, whereas 17\% (17/98) of the apps offered COVID-19-related information. Although most apps included a privacy policy, only a third of the apps presented it before account creation. In total, 82\% (74/90) of privacy 
policies stated sharing data with third-party service providers. Half of the app development teams included academic institutions or health care providers.

Conclusions: Only a few self-guided CBT-based apps offer comprehensive CBT programs or suicide risk management resources. Sharing of users' data is widespread, highlighting shortcomings in health app market governance. To fulfill their potential, self-guided CBT-based apps should follow evidence-based clinical guidelines, be patient centered, and enhance users' data security.

(J Med Internet Res 2021;23(7):e27619) doi: 10.2196/27619

\section{KEYWORDS}

cognitive behavioral therapy; CBT; depression; mobile applications; apps; telemedicine; mHealth; self-guided CBT-based apps; self-management; mobile phone

\section{Introduction}

\section{Background}

Mental health disorders affect 1 in 10 people globally [1], of which approximately 300 million are affected by depression [2]. At least half of the affected people remain untreated [3-5] because of many reasons [6-8], including low perceived need for treatment and self-reliance [7,8], stigma [9], difficulty accessing specialist care [10], fragmentation of the mental health care system [11], and high costs of treatment [12]. Access to psychiatrists and clinical psychologists is challenging, particularly in low- and middle-income countries [13] and for people of lower socioeconomic status, poorer health, and rural and hard-to-reach communities in high-income economies $[14,15]$. Since the onset of the COVID-19 pandemic, these inadequacies have been exacerbated by physical isolation, and fear and uncertainty $[16,17]$ led to a sudden increase in mental health concerns [18].

Cognitive behavioral therapy (CBT), one of the most widely used and researched forms of psychotherapy [19], is effective in treating a wide range of mental disorders, including depression [20-22]. CBT is a "structured, time-limited, present-focused" [23] therapy that promotes behavioral adaptation by coaching users to use a variety of tailored cognitive and behavioral techniques [24]. Traditional face-to-face CBT is costly, time-consuming, and subject to the availability of trained providers [10], limiting accessibility. To increase access to therapy, a number of internet-based CBT (iCBT) programs [25-27] offer an acceptable and effective alternative [28-30]. Therapist-guided iCBT has been shown to be as effective as face-to-face sessions [28], whereas self-guided interventions, albeit effective, are not at par with guided web-based programs [30-32].

Over the last decade, there has been increasing interest in using smartphone apps to support mental health disorder management and well-being [33], which has been further intensified since the COVID-19 pandemic [34,35]. Recent reports indicate that nearly 320,000 health apps [36] are available in major app stores, of which more than 10,000 are mental health apps [37]. Smartphone penetration is increasing worldwide, particularly in high-income countries [38], making apps a useful means to improve access to care for people unable or unwilling to consult a health care provider by offering interventions to be used at the time and place of the user's convenience at low cost $[39,40]$.
Apps can improve patient activation and disease self-management by increasing access to information and facilitating communication with health care providers and peers [41]. Two recent reviews, comprising one systematic review and one umbrella review $[42,43]$, concluded that apps were effective in improving users' emotional symptoms, including depression, although effect sizes varied according to the intervention and comparator groups, as well as the study quality. However, several shortcomings of mental health apps have been repeatedly described, including substantial dropout rates [44], mishandling of users' personal health information [45], poor app credibility, and lack of content personalization [41]. In addition, most health apps available in major app stores are not evidence based and have not been validated in clinical trials or approved by regulatory agencies $[37,46]$, underlining concerns about the effectiveness and safety of publicly available apps.

Previous work on self-guided CBT apps for depression noted only a few apps offering some evidence-based techniques, with limited user engagement features and a dominant focus solely on depression [47,48]. However, people with depression searching for an app will often retrieve a much wider variety of apps, including apps targeting several mental health disorders or those aimed at improving general well-being for healthy individuals. Therefore, we considered it important to conduct an updated assessment of self-guided CBT-based apps available in Google Play and Apple App Store encompassing well-being, general mental health, and depression apps to more closely align with real-life users' experience.

\section{Objective}

This study aims to systematically assess features, functionality, and congruence with evidence of self-guided CBT-based apps available in major app stores, targeting users affected by depression.

\section{Methods}

\section{Overview}

We developed a rigorous systematic assessment based on systematic literature review methodology, as used in several other studies [49-52]. The process included a systematic search for apps, two-step selection, and assessment following an exhaustive set of criteria developed by the research team. 


\section{Development of Assessment Criteria}

The assessment criteria aimed to provide an in-depth and holistic analysis of the apps, including clinical and technical characteristics. CBT-related features constitute a fundamental aspect of the overall appraisal, particularly the assessed apps' content compliance with evidence-based practice, as all health apps should ideally be based on sound evidence. Technical characteristics were included in the assessment if they were available in the app, app store description, or associated website and were not dependent on the assessor's subjective opinion or required access to the app's back-end data. The form was divided into three sections:

1. General characteristics extracted from the app store description, including developer, platform, app version number, category and ratings, number of downloads, cost, country of origin, languages featured in the app, target group, scope of the app, and therapy modalities offered by the app.

2. CBT-related features, based on Cognitive Behavior Therapy: Basics and Beyond by Judith Beck [53], a CBT competence framework [54] developed by the Improving Access to Psychological Therapies program in the United Kingdom, and a literature review of iCBT clinical trial protocols to identify distinct characteristics relevant to digital interventions. They comprised the following (Multimedia Appendix 1):

- Evidence-based CBT techniques, as described in the reference sources mentioned earlier, are routinely used in face-to-face practice: psychoeducation, about depression and CBT; behavioral activation (BA), including activity and task scheduling, suggestion of pleasurable activities, and monitoring of completed activities; cognitive restructuring, including assessment of automatic thoughts and core beliefs using thought records and completing behavioral experiments to challenge automatic thoughts and core beliefs; and other techniques frequently used in CBT, including problem solving, relaxation, and exposure techniques for comorbid anxiety.

- $\quad$ Procedures related to the structure offace-to-face CBT sessions: CBT sessions are highly structured and offer users strategies to cope after the end of therapy. We assessed whether relevant components of CBT sessions were offered, including structured, modular sessions, mood monitoring, suicide risk assessment, goal setting, homework assignment, therapeutic alliance [55], and coping strategies after completing the program. Following Tremain et al [55], we conceptualized the therapeutic alliance for self-guided interventions as strategies that encourage users' engagement with the app and adherence to assigned tasks, such as gamification, notifications, and reminders.

- Other information, including access to professional advice for distressed users, information related to the mental health impact of the COVID-19 pandemic as a proxy for continuous improvement of app content, and other techniques not mentioned elsewhere.
3. Technical aspects and quality assurance of the app, based on an assessment framework developed by our center [51,52], comprising ease-of-use, app credibility, presence of advertisements, privacy and security safeguards, including thoroughness of the privacy policy, privacy settings, and authentication to access the app content, among others. App credibility included appropriately referenced app content, qualifications of the app development team, presence of information does not replace provider's advice disclaimers, and published evidence of app effectiveness, assessed by searching PubMed for publications using the app name as keyword.

\section{App Selection}

\section{App Search}

A systematic search for apps available in the Apple App Store and Google Play Store was performed on February 19, 2020, in 42matters [56], a proprietary database, using the search terms cognitive behavioral therapy, cognitive behavioural therapy, cognitive therapy, CBT, behavioral therapy, behavioural therapy, behavioral activation, behavioural activation, online therapy, psychotherapy, counselling, and talking therapy. A total of 4 app store categories were included: education, health and fitness, lifestyle, and medical. For apps available in only one app store, a web search was performed to look for the other version, and if available, it was downloaded and assessed.

\section{Eligibility Criteria}

We included apps described as based on CBT, exclusively or associated to other psychotherapeutic modalities; offering CBT-based activities, exclusively or associated to other psychotherapeutic modalities; aiming to improve mood and well-being for people with low mood or depression and targeting depression alone or associated with another mental disorder; uploaded or updated from August 1, 2018, as regular updates of an app seem to directly affect app quality [57]; free, freemium (app is free to download but requires payment to activate extra features), or paid; available for download in the Apple App Store or Google Play Store; and in English.

We excluded apps offering CBT for other mental health disorders (ie, standalone anxiety, insomnia, posttraumatic stress disorder, etc); offering non-CBT-based mood recording or journaling, as referred to in the app store description; offering health care provider- or counselor-guided CBT modules, targeting health care providers or caregivers of a person affected by depression; offering teleconsultation services with physicians, psychologists, counselors, or other health care providers; removed from the app stores at the time of download, requiring a sign-up code provided by an institution, or inaccessible after two attempts due to technical problems; and in a language other than English.

\section{App Assessment}

App selection followed a systematic, two-step process. We first screened the app title and app store description from the 42matters search output and downloaded all apps included in the first step to assess eligibility. All assessments were performed using a Samsung Galaxy J7 Pro (Android 9) and 
iPhone 7 (iOS 13.3.1). If apps were available in both app stores, both versions were assessed to account for any difference in functionalities, and each version was included and counted separately. Individual apps belonging to a suite of related apps were combined and counted as one app.

Eligible apps were then assessed by the researcher (a medical doctor) for all available CBT techniques. If the app presented a modular intervention, it was used repeatedly to complete all modules. For consistency of assessments, a user persona was developed outlining demographic information, personal and medical history, responses to assessment questionnaires, and opening statements for conversational agent dialogs.

\section{Data Analysis}

Descriptive statistics were used to analyze the data. The study results were tabulated and reported as a narrative synthesis.
Data extraction and analysis were performed using Microsoft Excel.

\section{Results}

\section{Overview}

The keyword search retrieved 1955 results after duplicates were removed, of which 140 apps were downloaded and 100 apps were included in this analysis. A total of 3 apps (ie, eGuru Depression [58], eGuru Mood Diary [59], and eGuru Thought Diary [60]) belonged to a suite of related apps and were analyzed together as one app. Therefore, 98 apps were finally included in the analysis. The app search and selection processes are summarized in Figure 1. Multimedia Appendix 2 presents the list of assessed apps and a summary of CBT-related features.

Figure 1. App selection flowchart. CBT: cognitive behavioral therapy.

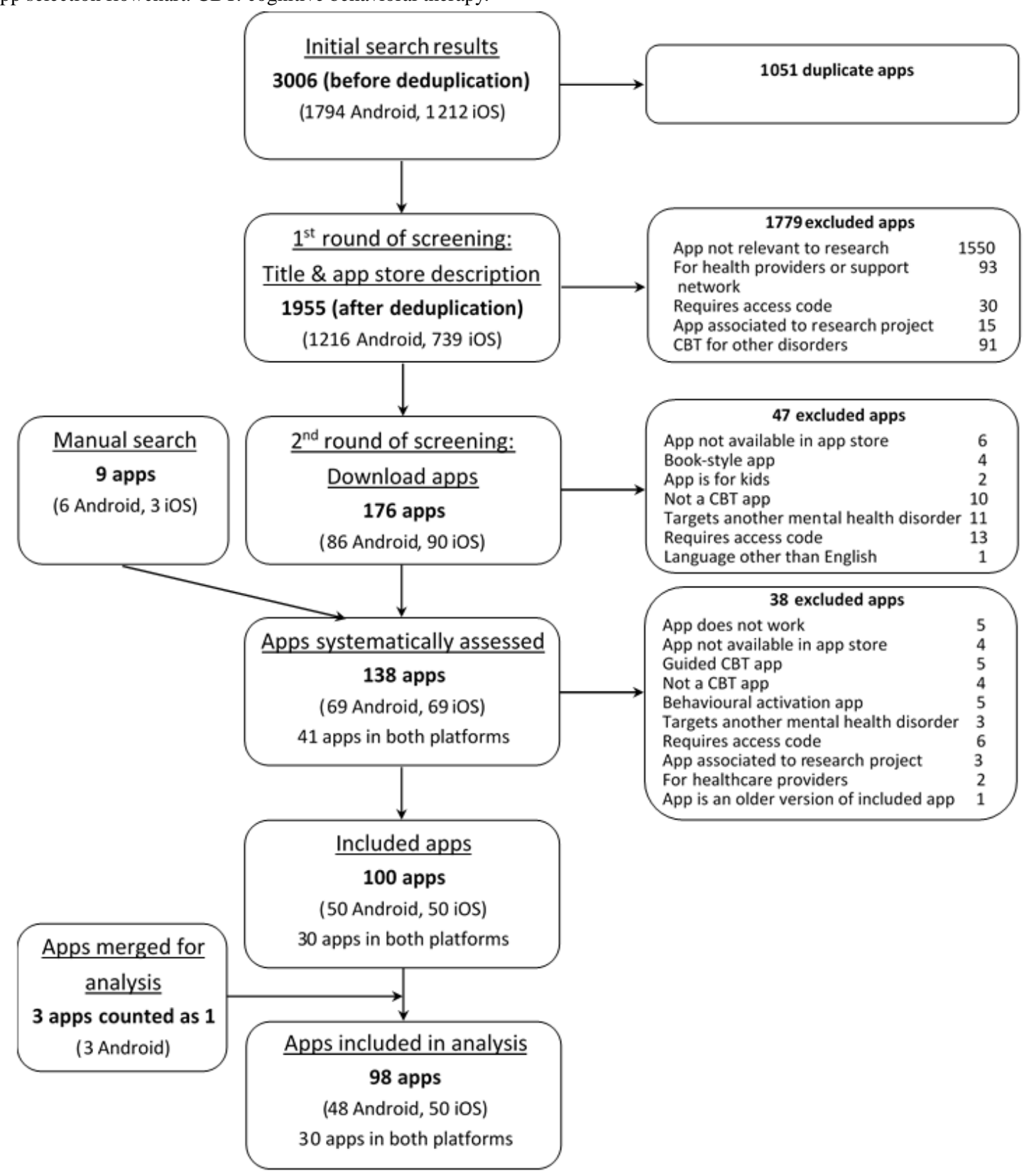




\section{General Characteristics of Apps}

Table 1 summarizes the characteristics of the included apps. Apps were grouped into three distinct categories: (1) well-being apps, providing CBT-based activities to improve users' general well-being; (2) mental health apps, offering self-guided activities to manage two or more common mental health disorders, including depression; and (3) depression apps offering self-guided CBT exclusively for depression.

There were 48 Android apps and 50 iOS apps. A total of 30 apps were available on both platforms, 18 were Android-only apps and 20 were iOS-only apps. A total of 74\% (73/98) of apps belonged to the health and fitness app store category, whereas $19 \%$ (19/98) of apps were listed as medical apps. A total of $27 \%$ (13/48) of Android apps were downloaded more than 100,000 times, including 11 mental health apps, 1 depression app, and 1 well-being app. A total of 4 mental health apps (ie, Moodpath [61], Sanvello [62], Wysa [63], and Youper [64]) and 1 well-being app (ie, Reflectly [65]) were downloaded more than $1,000,000$ times. Three-quarter $(n=73)$ of the apps had users' ratings above 3.5 on a $1-5$ scale and $42 \%$ (41/98) of apps had ratings above 4.5. Apps were developed in 16 different countries (Table 2). 
Table 1. General characteristics of the included apps $(\mathrm{N}=98)$.

\begin{tabular}{|c|c|c|c|c|}
\hline \multirow[t]{2}{*}{ Feature } & \multicolumn{3}{|l|}{ App category, n (\%) } & \multirow[t]{2}{*}{ Total $(\mathrm{N}=98), \mathrm{n}(\%)$} \\
\hline & Well-being $(n=20)$ & Mental health $(n=65)$ & Depression $(n=13)$ & \\
\hline \multicolumn{5}{|l|}{ App store category } \\
\hline Education & $1(5)$ & $0(0)$ & $0(0)$ & $1(1)$ \\
\hline Health and fitness & $19(95)$ & $46(71)$ & $8(62)$ & $73(74)$ \\
\hline Lifestyle & $0(0)$ & $5(8)$ & $0(0)$ & $5(5)$ \\
\hline Medical & $0(0)$ & $14(22)$ & $5(38)$ & $19(19)$ \\
\hline \multicolumn{5}{|l|}{ App store rating } \\
\hline $3.6 \mathrm{star}$ to $5 \mathrm{star}$ & $15(75)$ & $52(80)$ & $6(46)$ & $73(74)$ \\
\hline $1 \mathrm{star}$ to $3.5 \mathrm{star}$ & $0(0)$ & $7(11)$ & $2(15)$ & $9(9)$ \\
\hline No ratings & $5(25)$ & $6(9)$ & $5(38)$ & $16(16)$ \\
\hline \multicolumn{5}{|l|}{ App cost } \\
\hline Free & $8(40)$ & $27(42)$ & $4(31)$ & $39(40)$ \\
\hline Free with in-app purchase & $11(55)$ & $28(43)$ & $9(69)$ & $48(49)$ \\
\hline Paid & $1(5)$ & $10(15)$ & $0(0)$ & $11(11)$ \\
\hline \multicolumn{5}{|l|}{ Language } \\
\hline English & $16(80)$ & $47(72)$ & $12(92)$ & $75(77)$ \\
\hline English and other languages & $4(20)$ & $18(28)$ & $1(8)$ & $23(23)$ \\
\hline \multicolumn{5}{|l|}{ Target user of the app } \\
\hline No target user & $20(100)$ & $65(100)$ & $11(85)$ & $96(98)$ \\
\hline Youth (ages 12-18 years) & $0(0)$ & $0(0)$ & $2(15)$ & $2(2)$ \\
\hline \multicolumn{5}{|c|}{ Psychotherapy modalities used by the app } \\
\hline $\mathrm{CBT}^{\mathrm{a}}$ & $8(40)$ & $31(48)$ & $9(69)$ & $48(49)$ \\
\hline CBT and other modalities & $12(60)$ & $34(52)$ & $4(31)$ & $50(51)$ \\
\hline \multicolumn{5}{|c|}{ Number of evidence-based CBT techniques offered by the app } \\
\hline 0 & $5(25)$ & $4(6)$ & $0(0)$ & $9(9)$ \\
\hline 1 & $3(15)$ & $6(9)$ & $1(8)$ & $10(10)$ \\
\hline 2 & $11(55)$ & $25(34)$ & $2(15)$ & $38(39)$ \\
\hline 3 & $1(10)$ & $10(20)$ & $2(15)$ & $13(13)$ \\
\hline 4 & $0(0)$ & $16(23)$ & $8(62)$ & $24(24)$ \\
\hline 5 & $0(0)$ & $4(8)$ & $0(0)$ & $4(4)$ \\
\hline 6 & $0(0)$ & $0(0)$ & $0(0)$ & $0(0)$ \\
\hline \multicolumn{5}{|c|}{ Emergency contact information for users at risk of suicide } \\
\hline Yes & $2(10)$ & $23(35)$ & $8(62)$ & $33(34)$ \\
\hline No & $18(90)$ & $42(65)$ & $5(38)$ & $65(66)$ \\
\hline \multicolumn{5}{|c|}{ Information related to COVID-19 pandemic } \\
\hline Yes & $0(0)$ & $16(25)$ & $1(8)$ & $17(17)$ \\
\hline No & $20(100)$ & $49(75)$ & $12(92)$ & $81(83)$ \\
\hline \multicolumn{5}{|l|}{ App works as intended ${ }^{b}$} \\
\hline Yes & $18(90)$ & $62(95)$ & $12(92)$ & $92(94)$ \\
\hline No & $2(10)$ & $3(5)$ & $1(8)$ & $6(6)$ \\
\hline
\end{tabular}

${ }^{\mathrm{a} C B T}$ : cognitive behavioral therapy. 
${ }^{\mathrm{b}}$ Did not malfunction or crash during usage.

Table 2. List of countries where the self-guided cognitive behavioral therapy-based apps were developed (N=98).

\begin{tabular}{|c|c|c|c|c|}
\hline \multirow[t]{2}{*}{ Country } & \multicolumn{3}{|l|}{ App category, $\mathrm{n}(\%)$} & \multirow[t]{2}{*}{ Total, n (\%) } \\
\hline & Well-being $(\mathrm{n}=20)$ & Mental health $(n=65)$ & Depression $(n=13)$ & \\
\hline Australia & $0(0)$ & $4(6)$ & $2(15)$ & $6(6)$ \\
\hline Bulgaria & $2(10)$ & $0(0)$ & $0(0)$ & $2(2)$ \\
\hline Canada & $1(5)$ & $1(2)$ & $3(23)$ & $5(5)$ \\
\hline Colombia & $0(0)$ & $1(2)$ & $0(0)$ & $1(1)$ \\
\hline Cyprus and Belarus & $1(5)$ & $0(0)$ & $0(0)$ & $1(1)$ \\
\hline Denmark & $2(10)$ & $0(0)$ & $0(0)$ & $2(2)$ \\
\hline Germany & $0(0)$ & $4(6)$ & $0(0)$ & $4(4)$ \\
\hline India & $2(10)$ & $4(6)$ & $1(8)$ & $7(7)$ \\
\hline Israel & $0(0)$ & $2(3)$ & $0(0)$ & $2(2)$ \\
\hline New Zealand & $0(0)$ & $2(3)$ & $0(0)$ & $2(2)$ \\
\hline Norway & $0(0)$ & $2(3)$ & $1(8)$ & $3(3)$ \\
\hline Poland & $2(10)$ & $3(5)$ & $0(0)$ & $5(5)$ \\
\hline Sweden & $2(10)$ & $0(0)$ & $0(0)$ & $2(2)$ \\
\hline The Netherlands & $0(0)$ & $1(2)$ & $0(0)$ & $1(1)$ \\
\hline United Kingdom & $0(0)$ & $10(15)$ & $2(15)$ & $12(12)$ \\
\hline United States & $6(30)$ & $28(43)$ & $4(31)$ & $38(39)$ \\
\hline Unknown & $2(10)$ & $3(5)$ & $0(0)$ & $5(5)$ \\
\hline
\end{tabular}

A total of $25 \%(16 / 65)$ of mental health apps and $8 \%(1 / 13)$ of depression apps offered advice to manage the uncertainties and anxiety associated with COVID-19. In addition, 2 apps offered their subscription-only content for free to support users during the pandemic.

\section{CBT-Related Features}

\section{Overview}

Apps included a wide variety of CBT-related features, from structured CBT modules resembling face-to-face interventions to journaling applications, presenting guided questionnaires loosely based on the cognitive model. Table 3 outlines the CBT-related features offered by the apps. 
Table 3. Cognitive behavioral therapy-related techniques offered by the apps $(\mathrm{N}=98)$.

\begin{tabular}{|c|c|c|c|c|}
\hline \multirow[t]{2}{*}{ Feature } & \multicolumn{3}{|l|}{ App category, n (\%) } & \multirow[t]{2}{*}{ Total $(\mathrm{N}=98), \mathrm{n}(\%)$} \\
\hline & Well-being $(\mathrm{n}=20)$ & Mental health $(n=65)$ & Depression $(n=13)$ & \\
\hline \multicolumn{5}{|l|}{ Evidence-based $\mathrm{CBT}^{\mathrm{a}}$ techniques offered by the apps } \\
\hline Psychoeducation & $2(10)$ & $44(68)$ & $11(85)$ & $57(58)$ \\
\hline Behavioral activation & $2(10)$ & $28(43)$ & $11(85)$ & $41(42)$ \\
\hline Cognitive restructuring & $10(50)$ & $54(83)$ & $13(100)$ & $77(79)$ \\
\hline Problem solving & $4(20)$ & $6(9)$ & $2(15)$ & $12(12)$ \\
\hline Relaxation & $10(50)$ & $38(38)$ & $6(46)$ & $54(55)$ \\
\hline Exposure & $1(5)$ & $4(6)$ & $0(0)$ & $5(5)$ \\
\hline \multicolumn{5}{|l|}{ Procedures related to the structure of CBT sessions } \\
\hline Content offered in modules & $2(10)$ & $12(18)$ & $8(62)$ & $22(22)$ \\
\hline Current mood monitoring & $14(70)$ & $45(69)$ & $7(54)$ & $66(67)$ \\
\hline App administers screening questionnaire & $0(0)$ & $21(32)$ & $11(85)$ & $32(33)$ \\
\hline Suicide risk management & $2(10)$ & $23(35)$ & $9(69)$ & $34(35)$ \\
\hline Homework assignment & $0(0)$ & $16(25)$ & $4(31)$ & $20(20)$ \\
\hline Therapeutic alliance & $14(70)$ & $29(45)$ & $3(23)$ & $46(47)$ \\
\hline Strategies to cope after completing the modules & $2(10)$ & $3(5)$ & $4(31)$ & $9(9)$ \\
\hline \multicolumn{5}{|l|}{ Other functionalities } \\
\hline Journaling & $3(15)$ & $7(11)$ & $0(0)$ & $10(10)$ \\
\hline Gratitude or positive thought records & $2(10)$ & $10(15)$ & $0(0)$ & $12(12)$ \\
\hline Forums & $2(10)$ & $4(6)$ & $0(0)$ & $6(6)$ \\
\hline Web-based games & $1(5)$ & $4(6)$ & $0(0)$ & $6(6)$ \\
\hline Others & $1(5)$ & $18(28)$ & $5(38)$ & $24(25)$ \\
\hline
\end{tabular}

${ }^{\mathrm{a} C B T}$ : cognitive behavioral therapy.

\section{Evidence-Based CBT Techniques}

\section{Overview}

Most well-being apps $(19 / 20,95 \%)$ and over half of the mental health apps $(35 / 65,54 \%)$ offered up to two evidence-based CBT techniques, whereas most depression apps $(10 / 13,77 \%)$ offered three or four evidence-based techniques. Table 3 presents a summary of the CBT techniques assessed. A total of $25 \%(5 / 20)$ of well-being apps and 6\% (4/65) of mental health apps offered questionnaires or journaling templates based on the cognitive model but no evidence-based techniques.

\section{Psychoeducation}

Psychoeducation offered by the apps was mostly related to aspects of CBT, that is, explanations about cognitive distortions assessed in the app, automatic thoughts, and the CBT model. Information about depression was found in over a third of mental health apps $(15 / 44,34 \%)$ and most of the depression apps $(10 / 11,91 \%)$.

\section{Behavioral Activation}

A total of $42 \%$ (41/98) of apps offered BA techniques or modules frequently assisting users to track $(37 / 41,90 \%)$ or schedule $(30 / 41,73 \%)$ their activities, whereas $56 \%(23 / 41)$ of apps suggested activities to engage in.

\section{Cognitive Restructuring}

Overall, 79\% (77/98) of apps of the apps offered cognitive restructuring. Most apps (73/77, 95\%) guided users to identify automatic thoughts, whereas approximately two-third of the apps offered guidance to reframe automatic thoughts $(55 / 77$, $71 \%$ ) and identify the emotion linked to automatic thoughts $(50 / 77,65 \%)$ and/or cognitive distortions associated with automatic thoughts $(48 / 77,62 \%)$. Approximately two-third of the apps $(50 / 77,65 \%)$ obtained information using a template of follow-up questions similar to a thought record chart. A total of 6 apps $(6 / 77,8 \%)$ offered a noninteractive thought record template as their only feature.

\section{Problem Solving}

Problem-solving techniques or modules were offered by $12 \%$ (12/98) of apps, consisting of templates to plan a series of steps to solve a given problem.

\section{Relaxation}

A total of 54 apps offered relaxation modules. They consisted of mindfulness or meditation $(33 / 54,61 \%)$ apps or breathing exercise $(31 / 54,57 \%)$ apps. In total, $85 \%(46 / 54)$ of apps developed their own relaxation modules, whereas the rest offered links to other apps or websites. 


\section{Exposure Techniques for Comorbid Anxiety}

In total, 5\% (1/20) of well-being apps and 6\% (4/65) of mental health apps included techniques to expose users to anxiety-provoking stimuli. A total of 3 apps requested the user to record the exposure exercises, whereas 2 apps offered a reward for completed tasks.

\section{Procedures Related to the Structure of Face-to-Face CBT Sessions}

\section{Overview}

A total of 22 apps offered content in structured modules. These modules resembled face-to-face CBT sessions in the 3 depression apps. Furthermore, 9 apps offered advice on how to cope at the end of the modules.

\section{Mood Monitoring}

A total of 66 apps inquired about users' current mood, of which $20(30 \%)$ apps queried about reasons for low or depressed mood. In addition, 32 mental health and depression apps administered a screening questionnaire, particularly the depression module of the Patient Health Questionnaire (PHQ; PHQ-9: 20/32, 63\%; PHQ-8: 2/32, 6\%) alone or accompanied by another questionnaire, including Generalized Anxiety Disorder-7 (13 apps), Work and Social Adjustment Scale (3 apps), and Depression, Anxiety, and Stress Scale-21 (1 app). Moreover, $6 \%(2 / 32)$ of apps administered only Depression, Anxiety, and Stress Scale-21, and $25 \%(8 / 32)$ of apps administered a nonvalidated questionnaire.

\section{Suicide Risk Management}

Just over a third $(34 / 98,35 \%)$ of apps acknowledged suicide risk associated with depression by listing crisis management resources or actively inquiring about suicide risk. A total of $3 \%$ $(2 / 65)$ of mental health apps and $8 \%(1 / 13)$ of depression apps directly asked users about suicidal thoughts. Other apps, including 3\% (2/65) of mental health and 31\% (4/13) of depression apps passively assessed suicide risk through question 9 of the PHQ-9 ("thoughts that you would be better off dead or of hurting yourself in some way"). Although 4 apps responded to a positive answer to question 9 by offering access to crisis helplines, 2 apps did not actively respond to PHQ-9 results, instead offering a list of suicide prevention resources. A total of $6 \%(6 / 65)$ of mental health apps were conversational agents that responded to users' suicidal thoughts by offering access to crisis helplines directly through the app. Finally, $10 \%(2 / 20)$ of well-being apps, $20 \%(13 / 65)$ of mental health apps, and $31 \%$
(4/13) of depression apps presented a list of crisis helpline numbers without assessing suicide risk.

\section{Homework Assignment}

A total of $20 \%(20 / 98)$ of apps offered users homework activities. In total, 70\% (14/20) of apps assigned varied homework tasks, such as mood monitoring, reframing thoughts, BA, and relaxation exercises, whereas $30 \%(6 / 20)$ of apps consisted of a homework template to be completed between therapist visits.

\section{Therapeutic Alliance}

Overall, 46\% (46/98) of apps included one or more engagement strategies comprising push notifications or reminders to access app features $(31 / 46,67 \%)$, offering feedback or encouraging messages $(32 / 46,70 \%)$ and/or awarding badges or other virtual rewards for completed activities (18/46, 39\%). One conversational agent [66] was able to remember past conversations to further personalize the interaction.

\section{Other Features}

A total of $48 \%(47 / 98)$ of apps, including $45 \%(9 / 20)$ of well-being apps, $49 \%(32 / 65)$ of mental health apps, and $46 \%$ (6/13) of depression apps, also included one or more non-CBT-based features, particularly unstructured writing in the form of journals, gratitude, or positive thoughts; web-based games; and forums to connect to peers. A variety of other non-CBT-based functionalities were present in 1 or 2 assessed apps. These included inspiring quotes, visualization techniques, personality tests, access to self-help books, food records, management strategies for anxiety and panic attacks, safety plan templates, medication reminders, acceptance and self-compassion modules, music tracks, videos, physical exercise routines, and jokes.

\section{Technical Aspects and Quality Assurance}

\section{Overview}

In general, the assessed apps were easy to use and provided a logical and simple layout to navigate. Most apps worked as intended, and only $6 \%$ (6/98) apps either crashed while in use or included nonfunctional features. None of the assessed apps included advertisements. A total of 46\% (45/98) of apps allowed users to share data with health care providers, members of their support network, or other users of the app, using email or data syncing. Table 4 provides a summary of technical aspects and quality assurance of the apps. 
Table 4. Technical features and quality assurance of included apps (N=98).

\begin{tabular}{|c|c|c|c|c|}
\hline \multirow[t]{2}{*}{ Feature } & \multicolumn{3}{|c|}{ App category, $\mathrm{n}(\%)$} & \multirow{2}{*}{$\begin{array}{l}\text { Total }(\mathrm{N}=98), \mathrm{r} \\
(\%)\end{array}$} \\
\hline & $\begin{array}{l}\text { Well-being } \\
(\mathrm{n}=20)\end{array}$ & $\begin{array}{l}\text { Mental health } \\
(\mathrm{n}=65)\end{array}$ & $\begin{array}{l}\text { Depression } \\
(\mathrm{n}=13)\end{array}$ & \\
\hline \multicolumn{5}{|l|}{ App credibility } \\
\hline App content referenced or signed by the author & $0(0)$ & $29(45)$ & $9(69)$ & $38(39)$ \\
\hline $\begin{array}{l}\text { App includes a disclaimer that app information does not replace health } \\
\text { care provider's advice }\end{array}$ & $5(25)$ & $41(63)$ & $9(69)$ & $55(56)$ \\
\hline \multicolumn{5}{|l|}{ App development team mentioned in app content } \\
\hline $\begin{array}{l}\text { Government agency, academic institution, or nongovernment orga- } \\
\text { nization }\end{array}$ & $2(10)$ & $4(6)$ & $0(0)$ & $6(6)$ \\
\hline Health care professional & $1(5)$ & $36(55)$ & $11(85)$ & $48(49)$ \\
\hline Not declared & $17(85)$ & $25(38)$ & $2(15)$ & $44(45)$ \\
\hline \multicolumn{5}{|l|}{ Data privacy } \\
\hline Authentication required to access app & $12(60)$ & $46(71)$ & $9(69)$ & $67(68)$ \\
\hline App with a privacy policy ${ }^{a}$ & $18(90)$ & $59(91)$ & $12(92)$ & $89(91)$ \\
\hline Presented before account creation & $5(6)$ & $26(29)$ & $3(25)$ & $34(35)$ \\
\hline Explains how data are collected & $17(94)$ & $58(98)$ & $12(100)$ & $87(98)$ \\
\hline Shares information with third-party providers & $14(78)$ & $51(86)$ & $9(75)$ & $74(83)$ \\
\hline Shares contact details of Data Protection Officer & $7(35)$ & $13(22)$ & $0(0)$ & $20(22)$ \\
\hline App allows users to share data & $4(20)$ & $35(59)$ & $6(50)$ & $45(51)$ \\
\hline
\end{tabular}

${ }^{a}$ Percentage calculation was based on the number of apps with privacy policy (well-being apps: 18; mental health apps: 59; depression apps: 12; total: 89).

\section{App Credibility}

App content was referenced by $58 \%$ (57/98) of apps, including $10 \%(2 / 20)$ of well-being apps, $68 \%(44 / 65)$ of mental health apps, and $85 \%(11 / 13)$ of depression apps. Overall, just over half $(54 / 98,55 \%)$ of the apps were developed by academic institutions or included psychiatrists or psychologists in the development team. Disclaimers were present in 55 apps.

A total of 18 publications in peer-reviewed journals were available for $17 \%$ (17/98) of apps, including $25 \%(16 / 65)$ of mental health apps and $8 \%(1 / 13)$ of depression apps. A total of $33 \%(6 / 18)$ of papers included randomized controlled trials [67-72] reporting that apps or some specific app functions were effective in improving mood, anxiety, stress, or general well-being compared with active or waitlist controls. Other publications included pilot studies (3/18, 17\%) [73-75], secondary data analysis $(1 / 18,6 \%)$ [76], and app usage data analyses $(8 / 18,44 \%)$ [77-84] to assess user engagement and/or app effectiveness in decreasing users' symptoms.

\section{Data Privacy and Security}

Two-thirds $(67 / 98,68 \%)$ of the apps required authentication to access the app in the form of a password or less often a 4- to 6-digit numerical PIN. In addition, 49\% (48/98) of apps allowed users to customize the privacy settings in the app.

Most apps (90/98, 92\%) offered a privacy policy accessible from the app itself or through a link from the app store. The privacy policy was presented to users before account creation in only one-third of the apps $(34 / 98,35 \%)$. Most privacy policies $(88 / 90,98 \%)$ explained how users' personal data were collected, and more than three-fourth of which $(74 / 90,82 \%)$ stated that they shared data with third parties, often service providers. Nonetheless, only a few apps mentioned the names of the service providers or explicitly stated the type of data shared with them. A total of 2 apps stated that they shared data with advertising companies. Just over half of the privacy policies (47/90, 52\%) addressed the requirements of the General Data Protection Regulation mentioning the users' right to have their data corrected or deleted, whereas only $24 \%$ (22/90) privacy policies included the contact details of a data protection officer.

\section{Discussion}

\section{Principal Findings}

Our systematic assessment of 98 Android (including 5 apps downloaded more than 1,000,000 times) and iOS self-guided CBT apps revealed a heterogeneous group offering a range of evidence-based [53,54] and non-evidence-based CBT techniques.

Only 4 mental health apps offered all five evidence-based CBT techniques. Depression apps consistently offered three to four techniques, whereas most well-being and mental health apps offered two evidence-based techniques, suggesting that only a few apps currently offer comprehensive, self-guided CBT programs that may benefit users who are unable to access face-to-face psychotherapy. Cognitive restructuring was the 
most common technique across all app categories. Psychoeducation and BA were offered by most depression apps and approximately half of mental health apps; however, they were seldomly included in well-being apps. In addition, well-being and mental health apps frequently offered relaxation and mindfulness, whereas less than half of depression apps did so.

Our study's broad inclusion criteria aimed to resemble the options offered by app marketplaces when users search for a self-help app. Furthermore, classifying the apps into three distinct groups revealed that depression apps consistently offered more comprehensive programs, including at least three evidence-based techniques, whereas mental health and well-being apps were substantially less adherent. This finding differs from previous studies evaluating mental health apps $[52,57,85,86]$ and, more specifically, CBT for depression $[47,48]$ apps that consistently reported low adherence to evidence-based techniques. Huguet et al [47] evaluated 12 CBT and BA apps for depression available in Canada and reported a median adherence to core CBT criteria of $15 \%$, with 2 apps adhering to $75 \%$ of the criteria. Stawarz et al [48] analyzed 31 CBT apps and reported that most apps included cognitive restructuring and offered one or two CBT techniques.

Only one-third of the assessed apps offered resources to address suicide risk, whereas only a minority actively assessed users' suicide risk. App developers appear to disregard suicide risk when designing well-being and mental health apps, a worrying trend considering that most people dying by suicide are affected by a mental disorder $[87,88]$.

Although most apps included a privacy policy mentioning how users' personal data were used and shared, only a few provided sufficient details on the type of data shared or the companies with which the data were shared. Previous studies have shown that app developers often share user data with third parties, including Google and Facebook advertising [45,89], even when this is not stated in the privacy policy. Despite increasing concerns with regard to data privacy and security, apps still present considerable data management shortcomings, such as allowing third-party services to install pieces of code in the app to secretly access user data [90], as data sharing is a source of revenue, particularly for free apps. Notwithstanding the repeated calls for improvement, app development and publication processes remain unclear, allowing for loose interpretation or disregard of regulations. Further steps still need to be taken to ensure that user data are not misused, particularly highly sensitive data such as mental health-related information.

None of the assessed apps offered personalized content beyond including usernames or sex-appropriate pronouns when offering feedback or during dialogs with conversational agents. As a proxy to protect users' privacy, apps did not ask personal questions beyond name, sex, or age, nor did they inquire about relevant medical history. Other engagement features, such as push notifications, reminders, and gamification, were found in less than half of the included apps. Although the role of the bond between users and interventions in self-guided digital interventions remains unclear, it appears that tailoring content, personalization, and interactive features such as reminders, positive feedback, and supporting social interactions with other app users improve engagement and adherence [55].

One of the advantages of digital technologies is the possibility of continuous updates and improvements on the basis of contextual challenges or new clinical guidelines. However, as only $17 \%$ (17/98) of the included apps included information on the impact of COVID-19 and containment measures on mental health [17], it can be assumed that digital mental health providers do not fully leverage available technological opportunities.

Publications in peer-reviewed journals were available for 17 apps, of which only $6(35 \%)$ apps were evaluated using a randomized clinical trial, confirming the lack of evidence supporting the use of publicly available apps [91,92]. When evidence is available, clinical trials have consistently shown that apps improve mood in users affected by depression $[67,68]$ during and shortly after the completion of the trial, even if high dropout rates limit the validity of the results [44].

This study, using broad inclusion criteria, showed a great variety of CBT-based apps, from simple journaling apps to structured modules mirroring traditional CBT. Although such extensive selection may positively affect a larger number of users, it might be cumbersome and frustrating for users that specifically require a more structured self-guided CBT program, potentially hampering access to self-help tools. Mental health apps follow a continuum from well-being and lifestyle apps for healthy users to apps offering self-guided psychotherapy as an adjuvant to ongoing traditional therapy or as the sole therapy for people with mental health disorders. As such, the current app store categories may not be suitable for mental health apps. We propose the creation of a new, encompassing mental health category to include all well-being and mental health specific apps with subcategories targeting different mental health disorders, therapy modalities, and user groups. In addition, a wider overhaul of health app development and publication processes is required.

\section{Strengths and Limitations of the Study}

Our study had several strengths. Our process for searching, retrieving, and assessing included apps is grounded in systematic review methodology. The app search was implemented using the search engine of a commercial app database that allowed for a geographically unrestricted app search. Comprehensive assessment criteria were developed using reputable CBT manuals and a framework developed by our center to ensure comprehensive results.

However, this study has several limitations. Our search strategy included only CBT-related terms, potentially missing other apps offering CBT-based therapy for users with low mood or depression. We included apps offering self-guided CBT interventions, given the ethical limitations of using a simulated app persona when interacting with a health care provider, potentially excluding from our analysis more comprehensive apps. Apps linked to a specific provider or requiring an access code were also excluded from our study. Furthermore, the app store search was limited to only four categories with the maximum probability of retrieving relevant apps; therefore, we 
may have missed other apps outside these categories. Only apps in English were included in our study, potentially excluding relevant apps in other languages.

\section{Conclusions}

Self-guided CBT-based apps available in app marketplaces offer a wide range of interventions; however, only approximately one-third, particularly depression apps, included comprehensive CBT programs. App developers' access, use, and sharing of user data are unclear, raising concerns about the privacy and security of user data, and highlighting severe shortcomings in the governance of the health app market. Only a few apps offered suicide risk management resources or information on the current COVID-19 pandemic. The classification of mental health apps may benefit from the creation of a new mental health app category, including all well-being and specific disorder apps. To fulfill their potential, it is essential that self-guided CBT-based apps adhere to evidence-based clinical guidelines, be patient-centered, and offer enhanced and transparent data security measures.

\section{Acknowledgments}

LM gratefully acknowledges the National Technological University Research Scholarship (Lee Kong Chian School of Medicine) support for her PhD studentship, which enabled this work. JC's post at Imperial College London is supported by the National Institute for Health Research Northwest London Applied Research Collaboration. FVW and JC are supported by the National Research Foundation, Prime Minister's Office, Singapore, under its Campus for Research Excellence and Technological Enterprise program.

\section{Authors' Contributions}

LM had full access to all of the data in the study and took responsibility for the integrity of the data and the accuracy of the data analysis. LM, KG, and JC provided the concept and design of the study. LM acquired, analyzed and interpreted the data; performed statistical analysis; and provided administrative, technical and material support. The manuscript was drafted by LM and ACS. All authors contributed for critical revision of the manuscript for important intellectual content. JC obtained the funding. KG and JC were responsible for supervision.

\section{Conflicts of Interest}

None declared.

\section{Multimedia Appendix 1}

Assessment criteria for cognitive behavioral therapy-related features.

[DOCX File, 35 KB-Multimedia Appendix 1]

\section{Multimedia Appendix 2}

Characteristics of included apps.

[DOCX File, 54 KB-Multimedia Appendix 2]

\section{References}

1. GBD 2017 Disease and Injury Incidence and Prevalence Collaborators. Global, regional, and national incidence, prevalence, and years lived with disability for 354 diseases and injuries for 195 countries and territories, 1990-2017: a systematic analysis for the Global Burden of Disease Study 2017. Lancet 2018 Nov 10;392(10159):1789-1858 [FREE Full text] [doi: 10.1016/S0140-6736(18)32279-7] [Medline: 30496104]

2. Stigma and stigmatization within and beyond psychiatry. World Health Organization. 2017. URL: https://apps.who.int/iris/ bitstream/handle/10665/254610/WHO-MSD-MER-2017.2-eng. pdf;jsessionid=BB5A000A2E96A35EDC53EF0465D1F625? sequence=1 [accessed 2018-12-13]

3. Kohn R, Saxena S, Levav I, Saraceno B. The treatment gap in mental health care. Bull World Health Organ 2004 Nov;82(11):858-866 [FREE Full text] [Medline: 15640922]

4. Luitel NP, Jordans MJ, Kohrt BA, Rathod SD, Komproe IH. Treatment gap and barriers for mental health care: a cross-sectional community survey in Nepal. PLoS One 2017;12(8):e0183223 [FREE Full text] [doi: 10.1371/journal.pone.0183223] [Medline: 28817734]

5. Subramaniam M, Abdin E, Vaingankar JA, Shafie S, Chua HC, Tan WM, et al. Minding the treatment gap: results of the Singapore Mental Health Study. Soc Psychiatry Psychiatr Epidemiol 2020 Nov;55(11):1415-1424 [FREE Full text] [doi: 10.1007/s00127-019-01748-0] [Medline: 31317246]

6. Shi W, Shen Z, Wang S, Hall BJ. Barriers to professional mental health help-seeking among chinese adults: a systematic review. Front Psychiatry 2020;11:442 [FREE Full text] [doi: 10.3389/fpsyt.2020.00442] [Medline: 32508688] 
7. Mojtabai R, Olfson M, Sampson NA, Jin R, Druss B, Wang PS, et al. Barriers to mental health treatment: results from the National Comorbidity Survey Replication. Psychol Med 2011 Aug;41(8):1751-1761 [FREE Full text] [doi: 10.1017/S0033291710002291] [Medline: 21134315]

8. Andrade LH, Alonso J, Mneimneh Z, Wells JE, Al-Hamzawi A, Borges G, et al. Barriers to mental health treatment: results from the WHO World Mental Health surveys. Psychol Med 2014 Apr;44(6):1303-1317 [FREE Full text] [doi: 10.1017/S0033291713001943] [Medline: 23931656]

9. Prins M, Meadows G, Bobevski I, Graham A, Verhaak P, van der Meer K, et al. Perceived need for mental health care and barriers to care in the Netherlands and Australia. Soc Psychiatry Psychiatr Epidemiol 2011 Oct;46(10):1033-1044 [FREE Full text] [doi: 10.1007/s00127-010-0266-3] [Medline: 20686887]

10. Collins KA, Westra HA, Dozois DJ, Burns DD. Gaps in accessing treatment for anxiety and depression: challenges for the delivery of care. Clin Psychol Rev 2004 Sep;24(5):583-616. [doi: 10.1016/j.cpr.2004.06.001] [Medline: 15325746]

11. Raingruber B. Gaps in service in the recognition and treatment of depression and suicidal ideation within a four-county area. Perspect Psychiatr Care 2003;39(4):151-162. [doi: 10.1111/j.1744-6163.2003.00151.x] [Medline: 14737821]

12. Wang J. Perceived barriers to mental health service use among individuals with mental disorders in the Canadian general population. Med Care 2006 Feb;44(2):192-195. [doi: 10.1097/01.mlr.0000196954.67658.95] [Medline: 16434920]

13. Psychiatrists and Nurses (Per 100000 Population). World Health Organization. 2019. URL: https://apps.who.int/gho/data/ node.main.MHHR?lang=en [accessed 2020-08-11]

14. Navarro-Pérez JJ, Mestre M. Challenges and barriers in mental healthcare systems and their impact on the family: a systematic integrative review. Health Soc Care Community 2020 Sep;28(5):1366-1379. [doi: 10.1111/hsc.12968] [Medline: $\underline{32115797]}$

15. Mental health services in Australia. Australia: Australian Institute of Health and Welfare URL: https://www.aihw.gov.au/ reports/mental-health-services/mental-health-services-in-australia/report-contents/mental-health-workforce [accessed 2020-08-26]

16. Pfefferbaum B, North CS. Mental Health and the Covid-19 Pandemic. N Engl J Med 2020 Aug 06;383(6):510-512. [doi: 10.1056/NEJMp2008017] [Medline: 32283003]

17. Campion J, Javed A, Sartorius N, Marmot M. Addressing the public mental health challenge of COVID-19. Lancet Psychiatry 2020 Aug;7(8):657-659 [FREE Full text] [doi: 10.1016/S2215-0366(20)30240-6] [Medline: 32531299]

18. Pierce M, Hope H, Ford T, Hatch S, Hotopf M, John A, et al. Mental health before and during the COVID-19 pandemic: a longitudinal probability sample survey of the UK population. Lancet Psychiatry 2020 Oct;7(10):883-892 [FREE Full text] [doi: 10.1016/S2215-0366(20)30308-4] [Medline: 32707037]

19. David D, Cristea I, Hofmann SG. Why Cognitive Behavioral Therapy Is the Current Gold Standard of Psychotherapy. Front Psychiatry 2018;9:4 [FREE Full text] [doi: 10.3389/fpsyt.2018.00004] [Medline: 29434552]

20. Butler AC, Chapman JE, Forman EM, Beck AT. The empirical status of cognitive-behavioral therapy: a review of meta-analyses. Clin Psychol Rev 2006 Jan;26(1):17-31. [doi: 10.1016/j.cpr.2005.07.003] [Medline: 16199119]

21. Hofmann SG, Asnaani A, Vonk IJJ, Sawyer AT, Fang A. The Efficacy of Cognitive Behavioral Therapy: A Review of Meta-analyses. Cognit Ther Res 2012 Oct 1;36(5):427-440 [FREE Full text] [doi: 10.1007/s10608-012-9476-1] [Medline: 23459093]

22. Santoft F, Axelsson E, Öst L, Hedman-Lagerlöf M, Fust J, Hedman-Lagerlöf E. Cognitive behaviour therapy for depression in primary care: systematic review and meta-analysis. Psychol Med 2019 Jun;49(8):1266-1274. [doi: 10.1017/S0033291718004208] [Medline: 30688184]

23. Wenzel A, Brown G, Karlin B. Cognitive behavioral therapy for depression in veterans and military servicemembers: Therapist manual. Washington, DC: U.S. Department of Veterans Affairs; 2011. URL: https://www.mirecc.va.gov/docs/ cbt-d_manual_depression.pdf [accessed 2020-06-29]

24. Mennin DS, Ellard KK, Fresco DM, Gross JJ. United we stand: emphasizing commonalities across cognitive-behavioral therapies. Behav Ther 2013 Jun;44(2):234-248. [doi: 10.1016/j.beth.2013.02.004] [Medline: 23611074]

25. Christensen H, Griffiths KM, Korten A. Web-based cognitive behavior therapy: analysis of site usage and changes in depression and anxiety scores. J Med Internet Res 2002;4(1):e3 [FREE Full text] [doi: 10.2196/jmir.4.1.e3] [Medline: $\underline{11956035]}$

26. Proudfoot J, Ryden C, Everitt B, Shapiro DA, Goldberg D, Mann A, et al. Clinical efficacy of computerised cognitive-behavioural therapy for anxiety and depression in primary care: randomised controlled trial. Br J Psychiatry 2004 Jul;185:46-54 [FREE Full text] [Medline: 15231555]

27. Merry SN, Stasiak K, Shepherd M, Frampton C, Fleming T, Lucassen MFG. The effectiveness of SPARX, a computerised self help intervention for adolescents seeking help for depression: randomised controlled non-inferiority trial. BMJ 2012;344:e2598 [FREE Full text] [Medline: 22517917]

28. Carlbring P, Andersson G, Cuijpers P, Riper H, Hedman-Lagerlöf E. Internet-based vs. face-to-face cognitive behavior therapy for psychiatric and somatic disorders: an updated systematic review and meta-analysis. Cogn Behav Ther 2018 Jan;47(1):1-18. [doi: 10.1080/16506073.2017.1401115] [Medline: 29215315] 
29. Rost T, Stein J, Löbner M, Kersting A, Luck-Sikorski C, Riedel-Heller SG. User Acceptance of Computerized Cognitive Behavioral Therapy for Depression: Systematic Review. J Med Internet Res 2017 Sep 13;19(9):e309. [doi: 10.2196/jmir.7662] [Medline: 28903893]

30. Wells MJ, Owen JJ, McCray LW, Bishop LB, Eells TD, Brown GK, et al. Computer-Assisted Cognitive-Behavior Therapy for Depression in Primary Care: Systematic Review and Meta-Analysis. Prim Care Companion CNS Disord 2018 Mar 01;20(2):17r02196 [FREE Full text] [doi: 10.4088/PCC.17r02196] [Medline: 29570963]

31. Karyotaki E, Riper H, Twisk J, Hoogendoorn A, Kleiboer A, Mira A, et al. Efficacy of Self-guided Internet-Based Cognitive Behavioral Therapy in the Treatment of Depressive Symptoms: A Meta-analysis of Individual Participant Data. JAMA Psychiatry 2017 Apr 01;74(4):351-359. [doi: 10.1001/jamapsychiatry.2017.0044] [Medline: 28241179]

32. Berger T, Hämmerli K, Gubser N, Andersson G, Caspar F. Internet-based treatment of depression: a randomized controlled trial comparing guided with unguided self-help. Cogn Behav Ther 2011 Dec;40(4):251-266. [doi:

10.1080/16506073.2011.616531] [Medline: 22060248]

33. Topol E. Digital medicine: empowering both patients and clinicians. Lancet 2016 Aug 20;388(10046):740-741. [doi: 10.1016/S0140-6736(16)31355-1] [Medline: 27560260]

34. Torous J, Jän Myrick K, Rauseo-Ricupero N, Firth J. Digital Mental Health and COVID-19: Using Technology Today to Accelerate the Curve on Access and Quality Tomorrow. JMIR Ment Health 2020 Mar 26;7(3):e18848 [FREE Full text] [doi: 10.2196/18848] [Medline: 32213476]

35. Inkster B, O'Brien R, Selby E, Joshi S, Subramanian V, Kadaba M, et al. Digital Health Management During and Beyond the COVID-19 Pandemic: Opportunities, Barriers, and Recommendations. JMIR Ment Health 2020 Jul 06;7(7):e19246 [FREE Full text] [doi: 10.2196/19246] [Medline: $\underline{\text { 32484783] }}$

36. Aitken M, Clancy B, Nass D. The growing value of digital health - Evidence and impact on human health and the healthcare system. USA: IQVIA Institute for Human Data Science. 2017. URL: https://www.iqvia.com/insights/the-iqvia-institute/ reports/the-growing-value-of-digital-health\#: :text=The $\% 20$ use $\% 20$ of $\% 20$ such $\% 20$ Digital,estimated $\% 20 \% 247 \% 20$ billion\%20per\%20year [accessed 2018-07-11]

37. Torous J, Roberts LW. Needed Innovation in Digital Health and Smartphone Applications for Mental Health: Transparency and Trust. JAMA Psychiatry 2017 May 01;74(5):437-438. [doi: 10.1001/jamapsychiatry.2017.0262] [Medline: 28384700]

38. Newzoo. Penetration rate of smartphones in selected countries $2020 \mathrm{Graph}$. Statista 2020. URL: https://www.statista.com/ statistics/539395/smartphone-penetration-worldwide-by-country/ [accessed 2021-04-05]

39. Rebello TJ, Marques A, Gureje O, Pike KM. Innovative strategies for closing the mental health treatment gap globally. Curr Opin Psychiatry 2014 Jul;27(4):308-314. [doi: 10.1097/YCO.0000000000000068] [Medline: 24840160]

40. Musiat P, Goldstone P, Tarrier N. Understanding the acceptability of e-mental health--attitudes and expectations towards computerised self-help treatments for mental health problems. BMC Psychiatry 2014;14:109 [FREE Full text] [doi: 10.1186/1471-244X-14-109] [Medline: 24725765]

41. Vo V, Auroy L, Sarradon-Eck A. Patients' Perceptions of mHealth Apps: Meta-Ethnographic Review of Qualitative Studies. JMIR Mhealth Uhealth 2019 Jul 10;7(7):e13817 [FREE Full text] [doi: 10.2196/13817] [Medline: $\underline{\text { 31293246] }}$

42. Rathbone AL, Clarry L, Prescott J. Assessing the Efficacy of Mobile Health Apps Using the Basic Principles of Cognitive Behavioral Therapy: Systematic Review. J Med Internet Res 2017 Nov 28;19(11):e399 [FREE Full text] [doi: 10.2196/jmir.8598] [Medline: 29187342]

43. Lecomte T, Potvin S, Corbière M, Guay S, Samson C, Cloutier B, et al. Mobile Apps for Mental Health Issues: Meta-Review of Meta-Analyses. JMIR Mhealth Uhealth 2020 May 29;8(5):e17458 [FREE Full text] [doi: 10.2196/17458] [Medline: 32348289]

44. Torous J, Lipschitz J, Ng M, Firth J. Dropout rates in clinical trials of smartphone apps for depressive symptoms: A systematic review and meta-analysis. J Affect Disord 2020 Feb 15;263:413-419. [doi: 10.1016/j.jad.2019.11.167] [Medline: 31969272]

45. Huckvale K, Torous J, Larsen ME. Assessment of the Data Sharing and Privacy Practices of Smartphone Apps for Depression and Smoking Cessation. JAMA Netw Open 2019 Apr 05;2(4):e192542 [FREE Full text] [doi:

10.1001/jamanetworkopen.2019.2542] [Medline: 31002321]

46. Bates DW, Landman A, Levine DM. Health Apps and Health Policy: What Is Needed? JAMA 2018 Nov 20;320(19):1975-1976. [doi: 10.1001/jama.2018.14378] [Medline: $\underline{30326025]}$

47. Huguet A, Rao S, McGrath PJ, Wozney L, Wheaton M, Conrod J, et al. A Systematic Review of Cognitive Behavioral Therapy and Behavioral Activation Apps for Depression. PLoS One 2016;11(5):e0154248 [FREE Full text] [doi: 10.1371/journal.pone.0154248] [Medline: 27135410]

48. Stawarz K, Preist C, Tallon D, Wiles N, Coyle D. User Experience of Cognitive Behavioral Therapy Apps for Depression: An Analysis of App Functionality and User Reviews. J Med Internet Res 2018 Jun 06;20(6):e10120 [FREE Full text] [doi: 10.2196/10120] [Medline: 29875087]

49. Huckvale K, Adomaviciute S, Prieto JT, Leow MK, Car J. Smartphone apps for calculating insulin dose: a systematic assessment. BMC Med 2015;13:106 [FREE Full text] [doi: 10.1186/s12916-015-0314-7] [Medline: 25943590] 
50. Lum E, Jimenez G, Huang Z, Thai L, Semwal M, Boehm BO, et al. Decision Support and Alerts of Apps for Self-management of Blood Glucose for Type 2 Diabetes. JAMA 2019 Dec 16;321(15):1530-1532. [doi: 10.1001/jama.2019.1644] [Medline: $\underline{30990543]}$

51. van Galen LS, Xu X, Koh MJA, Thng S, Car J. Eczema apps conformance with clinical guidelines: a systematic assessment of functions, tools and content. Br J Dermatol 2020 Feb;182(2):444-453. [doi: 10.1111/bjd.18152] [Medline: 31179535]

52. Martinengo L, Van Galen L, Lum E, Kowalski M, Subramaniam M, Car J. Suicide prevention and depression apps' suicide risk assessment and management: a systematic assessment of adherence to clinical guidelines. BMC Med 2019 Dec 19;17(1):231 [FREE Full text] [doi: 10.1186/s12916-019-1461-z] [Medline: 31852455]

53. Beck J. Cognitive behavior therapy: Basics and beyond, 2nd ed. New York, NY. US: Guilford Press; 2011.

54. Roth A, Pilling S. The competences required to deliver effective cognitive and behavioural therapy for people with depression and with anxiety disorders. Improving Access to Psychological Therapies (IAPT) Programme, Department of Health. 2007. URL: https://www.uea.ac.uk/documents/20142/605327/norwich-medical-school-the-competences-required-todeliver-effective-cognitive-and- behavioural-therapy-for-people-with-depression-and-with-anxiety-disorders.pdf/ feaa5fd3-fee7-c597-c085-d2c98329edac?t=1576402736010 [accessed 2020-02-10]

55. Tremain H, McEnery C, Fletcher K, Murray G. The Therapeutic Alliance in Digital Mental Health Interventions for Serious Mental Illnesses: Narrative Review. JMIR Ment Health 2020 Aug 07;7(8):e17204 [FREE Full text] [doi: 10.2196/17204] [Medline: 32763881]

56. 42matters. URL: https://42matters.com/ [accessed 2020-02-19]

57. Wisniewski H, Liu G, Henson P, Vaidyam A, Hajratalli NK, Onnela J, et al. Understanding the quality, effectiveness and attributes of top-rated smartphone health apps. Evid Based Ment Health 2019 Feb;22(1):4-9. [doi: 10.1136/ebmental-2018-300069] [Medline: 30635262]

58. eGuru Depression. URL: https://play.google.com/store/apps/details?id=com.eguru4life.egurudepression\&hl=en_SG [accessed 2020-07-27]

59. eGuru Mood Diary. URL: https://play.google.com/store/apps/details?id=com.eguru4life.egurumooddiary\&hl=en SG [accessed 2020-03-20]

60. eGuru Thought Diary. URL: https://play.google.com/store/apps/details?id=com.eguru4life.eguruthoughtdiary\&hl=en SG [accessed 2020-07-27]

61. Moodpath - Depression \& Anxiety Test. URL: https://play.google.com/store/apps/details?id=de.moodpath.android\&hl=en_SG [accessed 2020-03-11]

62. Sanvello for Anxiety, Depression \& Stress. URL: $\underline{\text { https://play.google.com/store/apps/details?id=com.pacificalabs.pacifica }}$ [accessed 2020-03-12]

63. Wysa: stress \& anxiety therapy chatbot. URL: https://play.google.com/store/apps/details?id=bot.touchkin\&hl=en SG [accessed 2020-05-15]

64. Youper - Anxiety \& Depression. URL: https://play.google.com/store/apps/details?id=br.com.youper\&hl=en_SG [accessed 2020-05-15]

65. Reflectly - Journal / Diary. URL: https://play.google.com/store/apps/details?id=com.reflectlyApp [accessed 2020-03-16]

66. Happify. Happify. URL: https://www.happify.com/ [accessed 2020-05-15]

67. Bakker D, Kazantzis N, Rickwood D, Rickard N. A randomized controlled trial of three smartphone apps for enhancing public mental health. Behav Res Ther 2018 Oct;109:75-83. [doi: 10.1016/j.brat.2018.08.003] [Medline: $\underline{30125790]}$

68. Graham AK, Greene CJ, Kwasny MJ, Kaiser SM, Lieponis P, Powell T, et al. Coached Mobile App Platform for the Treatment of Depression and Anxiety Among Primary Care Patients: A Randomized Clinical Trial. JAMA Psychiatry 2020 Sep 01;77(9):906-914. [doi: 10.1001/jamapsychiatry.2020.1011] [Medline: 32432695]

69. Dahne J, Lejuez CW, Diaz VA, Player MS, Kustanowitz J, Felton JW, et al. Pilot Randomized Trial of a Self-Help Behavioral Activation Mobile App for Utilization in Primary Care. Behav Ther 2019 Jul;50(4):817-827. [doi: 10.1016/j.beth.2018.12.003] [Medline: $\underline{\text { 31208690] }}$

70. Hunter JF, Olah MS, Williams AL, Parks AC, Pressman SD. Effect of Brief Biofeedback via a Smartphone App on Stress Recovery: Randomized Experimental Study. JMIR Serious Games 2019 Nov 26;7(4):e15974 [FREE Full text] [doi: 10.2196/15974] [Medline: 31769761$]$

71. Moberg C, Niles A, Beermann D. Guided Self-Help Works: Randomized Waitlist Controlled Trial of Pacifica, a Mobile App Integrating Cognitive Behavioral Therapy and Mindfulness for Stress, Anxiety, and Depression. J Med Internet Res 2019 Jun 08;21(6):e12556 [FREE Full text] [doi: 10.2196/12556] [Medline: 31199319]

72. Fitzpatrick KK, Darcy A, Vierhile M. Delivering Cognitive Behavior Therapy to Young Adults With Symptoms of Depression and Anxiety Using a Fully Automated Conversational Agent (Woebot): A Randomized Controlled Trial. JMIR Ment Health 2017 Jun 06;4(2):e19 [FREE Full text] [doi: 10.2196/mental.7785] [Medline: 28588005]

73. Bakker D, Kazantzis N, Rickwood D, Rickard N. Development and Pilot Evaluation of Smartphone-Delivered Cognitive Behavior Therapy Strategies for Mood- and Anxiety-Related Problems: MoodMission. Cognitive and Behavioral Practice 2018 Nov;25(4):496-514. [doi: 10.1016/j.cbpra.2018.07.002] 
74. Mehrotra S, Sudhir P, Rao G, Thirthalli J, Srikanth TK. Development and Pilot Testing of an Internet-Based Self-Help Intervention for Depression for Indian Users. Behav Sci (Basel) 2018 Mar 22;8(4):36 [FREE Full text] [doi: 10.3390/bs8040036] [Medline: 29565278]

75. Mohr DC, Tomasino KN, Lattie EG, Palac HL, Kwasny MJ, Weingardt K, et al. IntelliCare: An Eclectic, Skills-Based App Suite for the Treatment of Depression and Anxiety. J Med Internet Res 2017 Jan 05;19(1):e10 [FREE Full text] [doi: 10.2196/jmir.6645] [Medline: 28057609]

76. Zhang R, Nicholas J, Knapp AA, Graham AK, Gray E, Kwasny MJ, et al. Clinically Meaningful Use of Mental Health Apps and its Effects on Depression: Mixed Methods Study. J Med Internet Res 2019 Dec 20;21(12):e15644 [FREE Full text] [doi: 10.2196/15644] [Medline: $\underline{\text { 31859682] }}$

77. Kinderman P, Hagan P, King S, Bowman J, Chahal J, Gan L, et al. The feasibility and effectiveness of Catch It, an innovative CBT smartphone app. BJPsych Open 2016 May;2(3):204-209 [FREE Full text] [doi: 10.1192/bjpo.bp.115.002436] [Medline: 27703777]

78. Inkster B, Sarda S, Subramanian V. An Empathy-Driven, Conversational Artificial Intelligence Agent (Wysa) for Digital Mental Well-Being: Real-World Data Evaluation Mixed-Methods Study. JMIR Mhealth Uhealth 2018 Nov 23;6(11):e12106 [FREE Full text] [doi: 10.2196/12106] [Medline: $\underline{\text { 30470676] }}$

79. Carpenter J, Crutchley P, Zilca RD, Schwartz HA, Smith LK, Cobb AM, et al. Seeing the "Big" Picture: Big Data Methods for Exploring Relationships Between Usage, Language, and Outcome in Internet Intervention Data. J Med Internet Res 2016 Aug 31;18(8):e241 [FREE Full text] [doi: 10.2196/jmir.5725] [Medline: 27580524]

80. Kwasny MJ, Schueller SM, Lattie E, Gray EL, Mohr DC. Exploring the Use of Multiple Mental Health Apps Within a Platform: Secondary Analysis of the IntelliCare Field Trial. JMIR Ment Health 2019 Mar 21;6(3):e11572 [FREE Full text] [doi: 10.2196/11572] [Medline: 30896433]

81. Lattie EG, Schueller SM, Sargent E, Stiles-Shields C, Tomasino KN, Corden ME, et al. Uptake and Usage of IntelliCare: A Publicly Available Suite of Mental Health and Well-Being Apps. Internet Interv 2016 May;4(2):152-158 [REEE Full text] [doi: 10.1016/j.invent.2016.06.003] [Medline: 27398319]

82. Parks AC, Williams AL, Kackloudis GM, Stafford JL, Boucher EM, Honomichl RD. The Effects of a Digital Well-Being Intervention on Patients With Chronic Conditions: Observational Study. J Med Internet Res 2020 Jan 10;22(1):e16211 [FREE Full text] [doi: 10.2196/16211] [Medline: $\underline{\text { 31922491] }}$

83. Bakker D, Rickard N. Engagement with a cognitive behavioural therapy mobile phone app predicts changes in mental health and wellbeing: MoodMission. Aust Psychol 2019 Mar 13;54(4):245-260. [doi: 10.1111/ap.12383]

84. Scherr S, Goering M. Is a Self-Monitoring App for Depression a Good Place for Additional Mental Health Information? Ecological Momentary Assessment of Mental Help Information Seeking among Smartphone Users. Health Communication 2019 Apr 26:1-9. [doi: 10.1080/10410236.2019.1606135]

85. Huckvale K, Nicholas J, Torous J, Larsen ME. Smartphone apps for the treatment of mental health conditions: status and considerations. Curr Opin Psychol 2020 Dec;36:65-70 [FREE Full text] [doi: 10.1016/j.copsyc.2020.04.008] [Medline: 32553848]

86. Nicholas J, Larsen ME, Proudfoot J, Christensen H. Mobile Apps for Bipolar Disorder: A Systematic Review of Features and Content Quality. J Med Internet Res 2015;17(8):e198 [FREE Full text] [doi: 10.2196/jmir.4581] [Medline: 26283290]

87. World Health Organization. Preventing suicide: A global imperative. Geneva: World Health Organization; 2014. URL: https://www.who.int/mental health/suicide-prevention/world report 2014/en/ [accessed 2019-01-03]

88. Hawton K, Casañas I Comabella C, Haw C, Saunders K. Risk factors for suicide in individuals with depression: a systematic review. J Affect Disord 2013 May;147(1-3):17-28. [doi: 10.1016/j.jad.2013.01.004] [Medline: 23411024]

89. Rosenfeld L, Torous J, Vahia IV. Data Security and Privacy in Apps for Dementia: An Analysis of Existing Privacy Policies. Am J Geriatr Psychiatry 2017 Aug;25(8):873-877. [doi: 10.1016/j.jagp.2017.04.009] [Medline: 28645535]

90. Razaghpanah A, Nithyanand R, Vallina-Rodriguez N. Apps, trackers, privacy, and regulators: a global study of the mobile tracking ecosystem. 2018 Presented at: Proceedings of the Network and Distributed Systems Security (NDSS) Symposium; 2018; San Diego, CA, USA p. 1-15. [doi: 10.14722/ndss.2018.23353]

91. Marshall JM, Dunstan DA, Bartik W. Apps With Maps-Anxiety and Depression Mobile Apps With Evidence-Based Frameworks: Systematic Search of Major App Stores. JMIR Ment Health 2020 Jun 24;7(6):e16525 [FREE Full text] [doi: 10.2196/16525] [Medline: 32579127]

92. Lattie EG, Adkins EC, Winquist N, Stiles-Shields C, Wafford QE, Graham AK. Digital Mental Health Interventions for Depression, Anxiety, and Enhancement of Psychological Well-Being Among College Students: Systematic Review. J Med Internet Res 2019 Jul 22;21(7):e12869 [FREE Full text] [doi: 10.2196/12869] [Medline: 31333198]

\section{Abbreviations}

BA: behavioral activation

CBT: cognitive behavioral therapy

iCBT: internet-based cognitive behavioral therapy

PHQ: Patient Health Questionnaire 


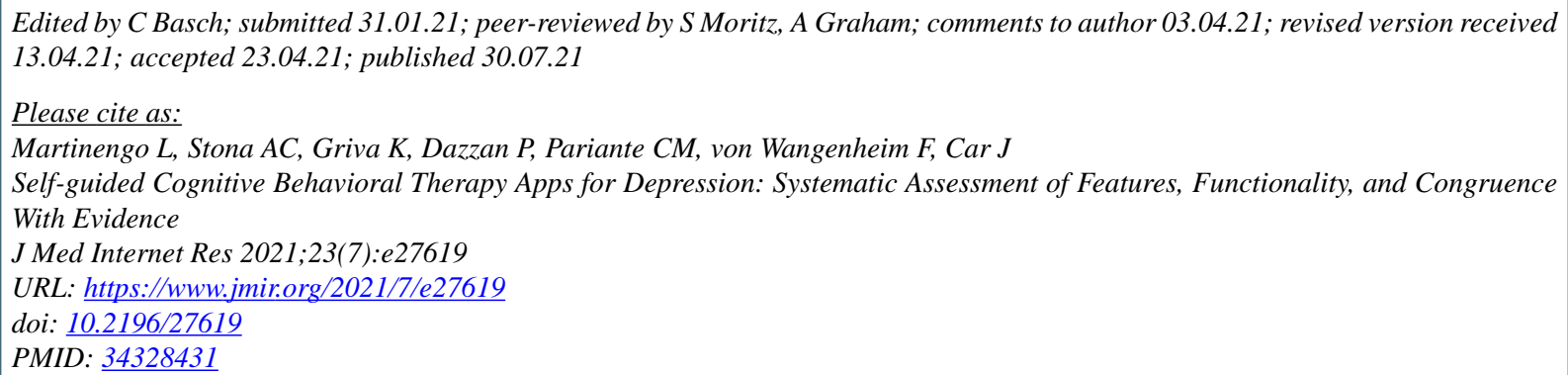

(CLaura Martinengo, Anne-Claire Stona, Konstadina Griva, Paola Dazzan, Carmine Maria Pariante, Florian von Wangenheim, Josip Car. Originally published in the Journal of Medical Internet Research (https://www.jmir.org), 30.07.2021. This is an open-access article distributed under the terms of the Creative Commons Attribution License (https://creativecommons.org/licenses/by/4.0/), which permits unrestricted use, distribution, and reproduction in any medium, provided the original work, first published in the Journal of Medical Internet Research, is properly cited. The complete bibliographic information, a link to the original publication on https://www.jmir.org/, as well as this copyright and license information must be included. 